\title{
Neonatal Hyperbilirubinemia in Japanese Neonates: Analysis of the Heme Oxygenase-1 Gene and Fetal Hemoglobin Composition in Cord Blood
}

\author{
MASAYO KANAI, KAZUHIRO AKABA, AYAKO SASAKI, MICHIHIKO SATO, TERUO HARANO, \\ SHIGEKI SHIBAHARA, HIROHISA KURACHI, TADASHI YOSHIDA, AND KIYOSHI HAYASAKA \\ Department of Pediatrics [M.K., K.A., A.S. K.H.], Central Laboratory for Research and Education [M.S.], \\ Department of Obstetrics and Gynecology [H.K.], Department of Biochemistry [T.Y.], Yamagata \\ University School of Medicine, Yamagata, 990-9585, Japan; Department of Biochemistry, Kawasaki \\ Medical School, Kurashiki, 701-0192, Japan [T.H.]; Department of Applied Physiology and Molecular \\ Biology, Tohoku University School of Medicine, Sendai, 980-8575, Japan [S.S.]
} \begin{abstract}
Neonatal hyperbilirubinemia is frequent and severe in Japa-
nese infants. Although the G71R mutation of the bilirubin uridine diphosphate-glucuronosyltransferase gene is associated with severe neonatal hyperbilirubinemia in this population, it accounts for only half of the neonates with severe hyperbilirubinemia. It was suggested that increased bilirubin production would also be associated with severe neonatal hyperbilirubinemia in Japanese infants. To elucidate the genetic factors causing severe hyperbilirubinemia in these patients, we studied two notable factors associated with bilirubin production: heme oxygenase-1, a key enzyme of heme metabolism, and fetal $\mathrm{Hb}$ composition, a factor possibly associated with heme load in neonates. We first determined the sequences of promoter and all coding regions of the heme oxygenase-1 gene in Japanese neonates who had undergone phototherapy, but found no mutation except for the polymorphic $(\mathrm{GT})_{\mathrm{n}}$ repeats in the promoter region. These repeats modulate the transcription of the heme oxygenase- 1 gene, and the longer repeat sequences are known to reduce the transcrip-
\end{abstract}

tion. We detected a significant difference in the allele frequencies of each number of $(\mathrm{GT})_{\mathrm{n}}$ repeats between Japanese and German populations. However, we could not find a relation between those polymorphisms and neonatal hyperbilirubinemia. We next analyzed the state of $\mathrm{Hb}$ switching of the $\gamma$ - to $\beta$-globin chain and the phenotype of $\gamma$-globin chain isoforms in cord blood. We found no relation between fetal $\mathrm{Hb}$ composition and neonatal hyperbilirubinemia. Further studies are required to elucidate genetic or environmental factors in neonatal hyperbilirubinemia in Japanese infants. (Pediatr Res 54: 165-171, 2003)
Abbreviations (EC 2.4.1.17)
HO-1, heme oxygenase-1 (EC 1.14.99.3)
CO, carbon monoxide
HbF, fetal hemoglobin
TCBR, transcutaneous bilirubinometer reading

B-UGT, bilirubin uridine diphosphate-glucuronosyltransferase
Unconjugated hyperbilirubinemia in the neonate is a physiologic and transitional phenomenon that is very common. Physiologic unconjugated hyperbilirubinemia of the neonate is called neonatal hyperbilirubinemia or neonatal jaundice. The term physiologic means that the neonate has no evidence of diseases causing unconjugated hyperbilirubinemia such as hemolytic anemias and does not carry variable risk factors associated with neonatal unconjugated hyperbilirubinemia such as maternal diabetes, prematurity, and so on (1).

Received October 23, 2002; accepted February 18, 2003

Correspondence: Kiyoshi Hayasaka, Department of Pediatrics, Yamagata University School of Medicine, 2-2-2 Iida-nishi, Yamagata 990-9585, Japan; e-mail: hayasaka@med.id.yamagata-u.ac.jp

DOI: 10.1203/01.PDR.0000072329.56635.35
Bilirubin production is increased in the neonate because of larger erythrocyte volume, shortened erythrocyte life span, heme and heme precursors degraded from the fetal extramedullary hematopoietic tissue, and, possibly, increased turnover of cytochromes (2). In addition, the ability to conjugate bilirubin is extremely low in the neonate; the B-UGT activity of neonates at term is about $1 \%$ of adult values (3). Neonatal hyperbilirubinemia is also probably associated with other factors such as an immaturity of hepatic uptake and intracellular transport, and increased enterohepatic circulation. Thus, an imbalance between the production and elimination of bilirubin results in various level of hyperbilirubinemia in every neonate.

The differences in the incidence and intensity of neonatal hyperbilirubinemia among different races are well known. 
Jaundice in Japanese neonates, as in other Asian neonates, is more frequent and more severe than in Caucasian and Negro neonates (2). We reported that the G71R mutation of the B-UGT gene was associated with neonatal hyperbilirubinemia in Japanese, Korean, and Chinese infants $(4,5)$. However, this mutation was detected in about $50 \%$ (allele frequency, 0.32) of Japanese neonates with severe hyperbilirubinemia and cannot explain the other half of Japanese neonates with severe hyperbilirubinemia.

$\mathrm{HO}$ is a rate-limiting enzyme in the heme metabolism and allows for the degradation of heme to biliverdin. Through this process, equimolar amounts of iron, biliverdin, and $\mathrm{CO}$ are yielded. Measurements of $\mathrm{CO}$ are recognized as useful indicators for bilirubin production. An increase in the bilirubin production, estimated by $\mathrm{CO}$ production, was suggested in Japanese or Asian neonates and would be associated with severe hyperbilirubinemia of those neonates (6-9).

To elucidate genetic factors causing severe hyperbilirubinemia in Japanese neonates, we studied two notable factors that may be associated with bilirubin production in the neonate. We first investigated the relation between neonatal hyperbilirubinemia and the HO-1 gene, which has a polymorphic $(\mathrm{GT})_{\mathrm{n}}$ dinucleotide repeat in its promoter region that modulates the level of its transcription $(10,11)$. In the perinatal period, $\mathrm{Hb}$ synthesis shifts markedly from $\mathrm{HbF}(\alpha 2 \gamma 2)$ to adult $\mathrm{Hb}(\mathrm{HbA} ; \alpha 2 \beta 2)$, which coincides with the shifting sites of erythropoiesis and with changes in other morphologic and biochemical characteristics of red blood cells. The state of the Hb switching probably reflects the changes in erythropoiesis. The $\gamma$-globin chain in $\mathrm{HbF}$ has three isoforms, ${ }^{\mathrm{G}} \gamma$ (136Gly, 75Ile), ${ }^{\mathrm{A}} \gamma^{\mathrm{I}}$ (136Ala, 75Ile), and ${ }^{\mathrm{A}} \gamma^{\mathrm{T}}$ (136Ala, $75 \mathrm{Thr})(12,13)$, and some genotypes would be associated with an increase in heme or heme precursor by making more vulnerable erythrocytes or by increasing the shunt bilirubin. We also studied whether the state of $\mathrm{Hb}$ switching of the $\gamma$ - to the $\beta$-globin gene and the heterogeneity of the $\gamma$-globin chain isoforms are associated with the severity of neonatal hyperbilirubinemia.

\section{METHODS}

\section{Subjects and Samples}

This study was approved by the Ethics Committee of the Yamagata University School of Medicine. With informed consent from the parents, we collected the umbilical cord blood of neonates born at Yamagata University Hospital between 1999 and 2001 for genomic DNA extraction and $\mathrm{Hb}$ separation. Twenty-seven subjects who had undergone phototherapy were recruited from the four hospitals in Yamagata prefecture between 1997 and 1998, and their peripheral blood was collected with their parents' consent for genomic DNA extraction. The neonates whose birth weights were $<2500 \mathrm{~g}$ and whose gestational age was $<36$ wk were excluded. We also excluded neonates who had factors that would affect the level of serum bilirubin such as hemolytic anemia, neonatal asphyxia, maternal diabetes, congenital heart or intestine malformation, infections, drug administrations, and parenteral fluid therapies. We finally studied 122 subjects with umbilical cord samples, three of whom underwent phototherapy. Genomic DNA samples from German controls, collected from 89 healthy younger adults at a Munich blood center in 1994, were also used.
Genomic DNA was extracted from the white blood cells by a standard method, and globin samples were prepared as described (14).

\section{Hyperbilirubinemia Assessment and Criteria for Phototherapy}

Hyperbilirubinemia of the neonate was assessed with a jaundice meter (model 102; Minolta, Osaka, Japan) once a day, at the same time, during hospitalization or at least during the first week of life. When the reading of the TCBR reached the criterion for further evaluation, total serum bilirubin concentration was measured. Phototherapy was initiated if the measured bilirubin level exceeded the criterion as follows: 102.6 $\mu \mathrm{M}$ at $\mathrm{d} 0,171 \mu \mathrm{M}$ at d 1,205.2 $\mu \mathrm{M}$ at d 2, 239.4 $\mu \mathrm{M}$ at d 3, $256.5 \mu \mathrm{M}$ at $\mathrm{d} 4,273.6 \mu \mathrm{M}$ at d 5, $290.7 \mu \mathrm{M}$ at $\mathrm{d}$ 6, and 307.8 $\mu \mathrm{M}$ at $\mathrm{d} 7$ or greater.

\section{B-UGT Gene Analysis}

The TATA element in the promoter region of the B-UGT gene was analyzed as previously reported (4). The G71R mutation of the B-UGT gene was studied by Esp3I restriction analysis.

\section{HO-1 Gene Analysis}

Sequence analysis of the promoter and cording regions of the HO-1 gene. The promoter region (up to 480 bp upstream from the initiation codon) and all coding regions of the HO-1 gene were amplified by PCR and their sequences were directly determined. Table 1 shows each primer set for PCR, designed based on genomic information of the HO-1 gene. Sequences were determined by the dideoy dyeterminator cycle method on an ABI PRISM Genetic Analyzer 310 (Applied Biosystems, Foster City, CA, U.S.A.).

$(G T)_{n}$ repeats analysis. The 5'-flanking region containing a $(\mathrm{GT})_{\mathrm{n}}$ repeat sequence of the HO-1 gene was amplified according to previous methods (11). The primer sequence and PCR condition are shown in Table 1. The size of the PCR product

Table 1. PCR primers for the analysis of the HO-1 gene

\begin{tabular}{cc}
\hline \multicolumn{1}{c}{ Exon } & \multicolumn{1}{c}{ Primers $\left(5^{\prime}\right.$ to $\left.3^{\prime}\right)$} \\
\hline $\begin{array}{c}\text { GT }) \text { n repeats region } \\
\text { GT-F** }{ }^{* *} \\
\text { GT-R }\end{array}$ & AGAGCCTGCAGCTTCTCAGA \\
Exon $1^{*}$ & ACAAAGTCTGGCCATAGGAC \\
PR-F & GCAAGCAGTCAGCAGAGGAT \\
1R & CACCTCCTGACTCCAGAGC \\
Exon 2 & \\
$2 \mathrm{~F}$ & AAAGCGATTGAGAACGTGGC \\
$2 \mathrm{R}$ & AGATGATTCTATTGGACATGC \\
Exon 3 & \\
$3 \mathrm{~F}$ & TGTGAAGAGGATTGTAGCGA \\
$3 \mathrm{R}$ & GTGTTAACCATGACCTATAGC \\
Exon 4 & \\
$4 \mathrm{~F}$ & TAAGGTCCTACCTTCAGCTG \\
$4 \mathrm{R}$ & GGCAATATAGCGAGAACCTG \\
Exon 5 & \\
$5 \mathrm{~F}$ & GCAGTGACTGTACCACAGAC \\
$5 \mathrm{R}$ & CCCTGAAAGCCTTCAGTGC \\
\hline
\end{tabular}

* $5 \%$ DMSO in the reaction buffer.

** Fluorescence labeled. 
was analyzed using a Genescan application on an ABI PRISM Genetic Analyzer 310 with Genescan-350 TAMRA (Applied Biosystems) as a size marker.

\section{Globin Chain Analysis}

Composition of each globin chain in $\mathrm{HbF}$ was analyzed using reverse-phase HPLC with a Wakosil 5C18-200 column $(4.6 \times 200 \mathrm{~mm})($ Wako Chemicals, Osaka, Japan) and Hitachi 638-30 (Hitachi, Ltd., Tokyo, Japan). The chromatograph was developed with the gradient of $30-43.6 \%$ acetonitrile in $0.1 \%$ trifluoroacetic acid for $80 \mathrm{~min}$ at $20^{\circ} \mathrm{C}$, and the flow rate was 1 $\mathrm{mL} / \mathrm{min}$. Absorbance at $220 \mathrm{~nm}$ was read using a UV monitor (Hitachi, Ltd.) and the relative quantities of each globin fraction were measured by the area ratio of the absorption. The percentage of $\mathrm{HbF}$ to total $\mathrm{Hb}(\mathrm{HbF} \%)$ was calculated as follows: $\mathrm{HbF} \%=$ total $\gamma \times 100 /[\beta+$ total $\gamma]$.

\section{Statistical Analysis}

The gestational age, birth weight, and ratio of breast-fed to formula-fed of the two groups were compared using the unpaired $t$ test. Comparisons of the distributions between the two groups were analyzed using $\chi^{2}$ test. Analysis of the TCBR among the three or six groups on each day was performed with the Kruskal-Wallis test, and TCBR of the two groups was compared using the Mann-Whitney $U$ test. Correlations between $\mathrm{HbF} \%$ and other variables were analyzed using simple regression. Characteristics of the three groups were analyzed by one-way ANOVA and Fisher's protected least significant difference.

\section{RESULTS}

Subjects' characteristics. One hundred and twenty-two subjects with umbilical cord blood samples and 27 subjects who had undergone phototherapy were recruited for this study. A total of 30 subjects underwent phototherapy (PT group) and another 119 subjects did not require any treatment (non-PT group). There was no significant difference between the PT and non-PT groups in birth weight, gestational age, and the ratio of breast-fed to formula-fed. We found heterozygous or homozygous G71R mutation of the B-UGT gene in 16 of 30 subjects (mutated allele frequency, 0.28) in the PT group and 38 of 119 (mutated allele frequency, 0.18) in the non-PT group. None of the subjects in the PT group and 20 in the non-PT group (mutated allele frequency, 0.08) had heterozygous (TA) $)_{7}$ mutation in the promoter of the B-UGT gene.

Mutation analysis of the promoter and coding regions of the HO-1 gene in Japanese neonates who had undergone phototherapy. We analyzed the sequences of the promoter and all coding regions of the HO- 1 gene in the five Japanese subjects who underwent phototherapy (PT group) and had neither G71R nor (TA) 7 mutations of the B-UGT gene. They showed no mutation in these regions except for the polymorphic and variable $(\mathrm{GT})_{\mathrm{n}}$ repeats in the promoter.

Comparison of the distribution of the numbers and genotypes of polymorphic $(G T)_{n}$ repeats in the $\mathrm{HO}-1$ gene in Japanese and German subjects. We first compared the distributions of allele frequencies at each number of $(\mathrm{GT})_{\mathrm{n}}$ repeats in the promoter of the HO-1 gene in Japanese and German subjects (Fig. 1A). One hundred and twenty-two subjects whose cord blood samples were collected were regarded as Japanese controls. To analyze the difference in the distribution of the allele frequency between Japanese and German subjects, we divided the numbers of $(\mathrm{GT})_{\mathrm{n}}$ repeats into three classes according to the previous methods. For the alleles of 26 or less, from 27 to 32, and 33 or greater, their numbers of repeats were designated as "S class allele," "M class allele," and "L class allele," respectively (11). Table $2 A$ shows the allele frequencies of S, M, and L classes in Japanese and German subjects. There was a significant difference in the allele distribution between these populations $(p<0.001)$. Analysis of the numbers of each allele class between Japanese and German subjects showed that the Japanese had significantly more $\mathrm{S}$ and $\mathrm{L}$ class alleles ( $p=0.006$ and $p<0.001$, respectively) and less $\mathrm{M}$ class alleles than did the Germans $(p<0.001)$. We also compared the genotypes determined by combination of the classes of two alleles in each subject. There was a significant difference in the distribution of the genotypes between Japanese and Germans $(p<0.001)$ (Table $2 A)$.

Comparison of the distribution of the numbers of polymorphic $(G T)_{n}$ repeats in the HO-1 gene in the Japanese PT and non-PT groups. To study whether the number of $(\mathrm{GT})_{\mathrm{n}}$ repeats was associated with the frequency and severity of neonatal hyperbilirubinemia in Japanese neonates, we compared these allele frequencies in Japanese neonates with and without phototherapy. There was no significant difference in the distribution of allele frequencies of $\mathrm{S}, \mathrm{M}$, and $\mathrm{L}$ classes between PT and non-PT groups (Fig. $1 B$ and Table $2 B$ ). To eliminate the effects of the G71R or (TA) $)_{7}$ mutations of the B-UGT gene, we excluded the subjects with those mutations from the groups and also found no significant difference between the PT and non-PT groups (Table 2C).

Similarly, there was no significant difference in the genotypes between the PT and non-PT groups, even in the subjects without the G71R or (TA) $)_{7}$ mutations (Table $2 C$ ).

Relation between the genotypes of polymorphic $(G T)_{n}$ repeats and TCBR. To confirm the effect of $(\mathrm{GT})_{\mathrm{n}}$ repeats on bilirubin metabolism of neonates, we also analyzed the relation between the genotypes and TCBR on $\mathrm{d} 0-5$ in Japanese neonates. We excluded the subjects with the G71R or (TA) mutations of the B-UGT gene and found no significant difference in TCBR among genotypes on d 0-5 (Fig. 2).

Hb composition by HPLC analysis in Japanese neonates. The compositions of the globin chains in cord blood samples were analyzed in 69 Japanese subjects without G71R or (TA) ${ }_{7}$ mutations of the B-UGT gene. The $\gamma$-globin chain in $\mathrm{HbF}$ has three isoforms, ${ }^{\mathrm{G}} \gamma,{ }^{\mathrm{A}} \gamma^{\mathrm{I}}$, and ${ }^{\mathrm{A}} \gamma^{\mathrm{T}}$, which were separated by HPLC analysis. The $\mathrm{HbF} \%$ were calculated and ranged between $70.2 \%$ and $93.3 \%$, and the mean values \pm SD were $84.7 \pm 5.4 \%$.

The proportion of ${ }^{\mathrm{G}} \gamma$-globin chain to total $\gamma$-globin chains $\left({ }^{\mathrm{G}} \gamma \%\right)$ in all except eight subjects $\left(<50 \%\right.$ of ${ }^{\mathrm{G}} \gamma \%$ or $\geq 80 \%$ of $\left.{ }^{\mathrm{G}} \gamma \%\right)$ ranged from 59.5 to $79.7 \%(70.4 \pm 3.8 \%$; mean $\pm \mathrm{SD})$ as in previous studies $(12,13,15-17)$. Two subjects with $<50 \%$ of ${ }^{\mathrm{G}} \gamma \%$ showed $40.9 \%$ and $37.0 \%$ of ${ }^{\mathrm{G}} \gamma \%$, and may be individuals with monosomy of the ${ }^{\mathrm{G}} \gamma$-globin gene $(13,17)$. Six subjects 

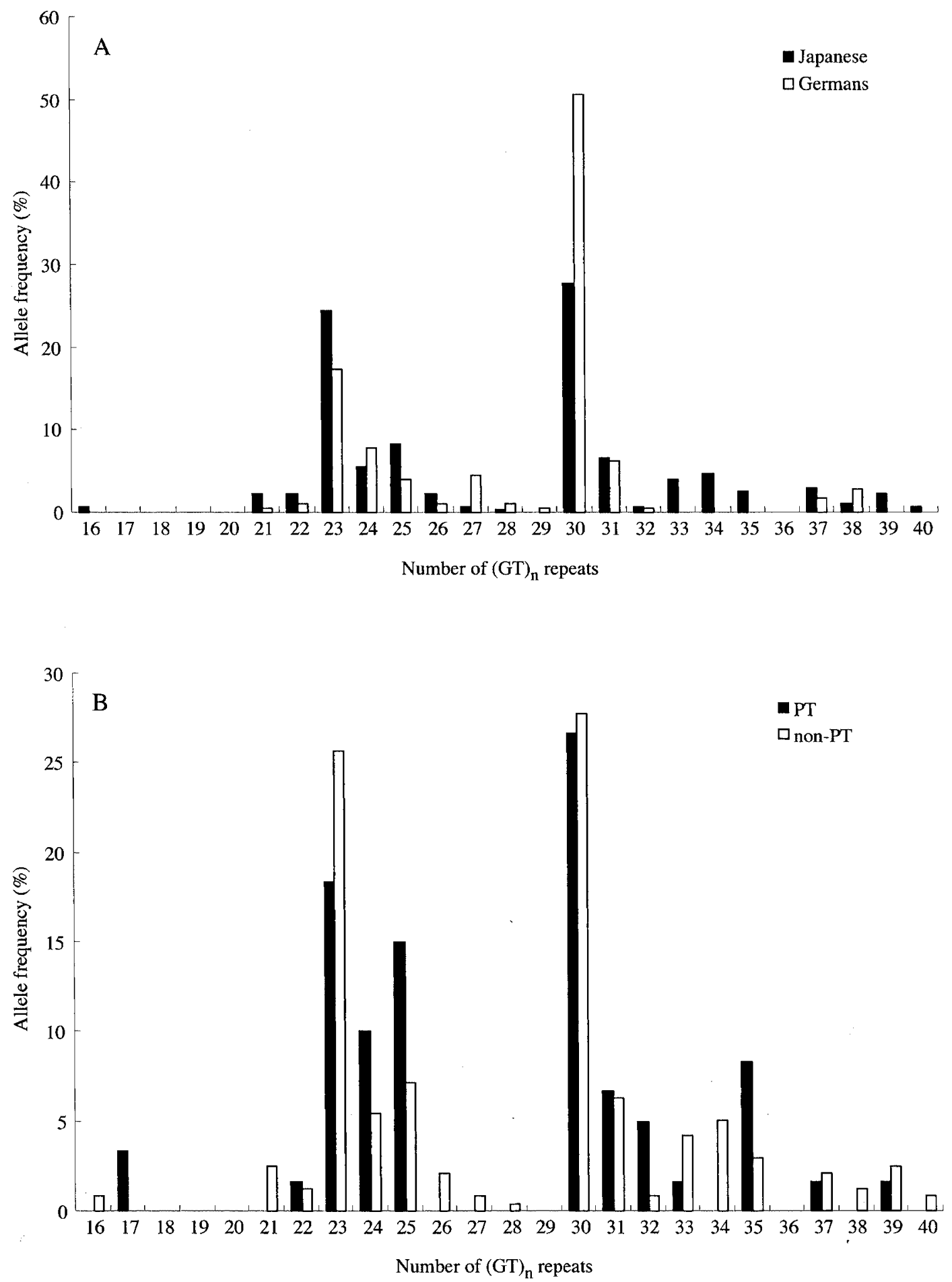

Figure 1. Distribution of the allele frequency at each number of (GT) repeats. (A) Comparison between Japanese $(n=244)$ and German $(n=188)$ subjects. (B) Comparison between the PT group $(n=60)$ and the non-PT group $(n=238)$ in Japanese neonates.

showed $\geq 80 \%$ of ${ }^{\mathrm{G}} \gamma \%$, and may have triple or quadruple $\gamma$-globin gene arrangements, as previously reported $(13,17)$.

The genotypes of the ${ }^{\mathrm{A}} \gamma$-globin chain compositions suggested from the data of HPLC analysis were as follows: 46 $(66.7 \%)$ of 69 subjects were ${ }^{\mathrm{A}} \gamma^{\mathrm{I}}$ homozygotes, $20(29.0 \%)$ ${ }^{\mathrm{A}} \gamma^{\mathrm{I} / \mathrm{A}} \gamma^{\mathrm{T}}$ heterozygotes, and $3(4.3 \%){ }^{\mathrm{A}} \gamma \mathrm{T}$ homozygotes. The allele frequency of the ${ }^{\mathrm{A}} \gamma^{\mathrm{T}}$ gene was calculated to 0.188 , which was comparable with those of previous studies $(12,15,16)$.
Relation between $\mathrm{HbF} \%$ or $\gamma$-globin chain composition and TCBR. According to the values of $\mathrm{HbF} \%$, we divided the subjects into three groups: the high $\mathrm{HbF} \%$ group, $>90 \%$ (mean $+1.0 \mathrm{SD}$ ) of $\mathrm{HbF} \%$; the middle $\mathrm{HbF} \%$ group, $80-90 \%$; low $\mathrm{HbF} \%$ group, $<80 \%$ (mean $-1.0 \mathrm{SD}$ ). Figure 3 shows the TCBR for these three groups on $\mathrm{d} 0-5$. There were correlation tendencies between the values of $\mathrm{HbF} \%$ and TCBR on $\mathrm{d} 3-5$. Significant differences were observed between the high $\mathrm{HbF} \%$ 
Table 2. Allele frequencies of the three classes and distribution of genotypes

A. In German and Japanese subjects

\begin{tabular}{|c|c|c|c|c|c|c|c|c|c|c|c|}
\hline & \multicolumn{3}{|c|}{ No. $(\%)$ of alleles } & & \multicolumn{6}{|c|}{ No. $(\%)$ of subjects } & \multirow[b]{3}{*}{ * } \\
\hline & $\mathrm{S}$ class & $\mathrm{M}$ class & $\mathrm{L}$ class & & SS & SM & SL & MM & ML & LL & \\
\hline Japanese & $111(45.5)$ & $87(35.7)$ & $46(18.8)$ & $*$ & $26(21.3)$ & $45(36.9)$ & $14(11.5)$ & $12(9.8)$ & $19(15.6)$ & $6(4.9)$ & \\
\hline \multicolumn{12}{|c|}{$* p<0.001$ by $\chi^{2}$ analysis. } \\
\hline \multicolumn{12}{|c|}{ B. In the Japanese PT and non-PT groups } \\
\hline With PT & $29(48.4)$ & $23(38.3)$ & $8(13.3)$ & NS & $6(20.0)$ & $14(46.6)$ & $3(10.0)$ & $2(6.7)$ & $5(16.7)$ & $0(0.0)$ & NS \\
\hline Without PT & $107(45.0)$ & $86(36.1)$ & 45 (18.9) & & $24(20.2)$ & $45(37.8)$ & $14(11.8)$ & $12(10.1)$ & $18(15.1)$ & $6(5.0)$ & \\
\hline
\end{tabular}

PT, phototherapy; NS, not significant by $\chi^{2}$ analysis.

C. In Japanese subjects in the PT and non-PT groups without G71R or (TA) $)_{7}$ mutations of the B-UGT gene

\begin{tabular}{|c|c|c|c|c|c|c|c|c|c|c|c|}
\hline & \multicolumn{3}{|c|}{ No. $(\%)$ of alleles } & & \multicolumn{6}{|c|}{ No. (\%) of subjects } & \\
\hline & $\mathrm{S}$ class & M class & L class & & SS & SM & SL & MM & ML & LL & \multirow{3}{*}{ NS } \\
\hline With PT & $13(46.4)$ & $10(35.7)$ & $5(17.9)$ & NS & $3(21.4)$ & $6(42.9)$ & $1(7.1)$ & $0(0.0)$ & $4(28.6)$ & $0(0.0)$ & \\
\hline Without PT & 55 (41.7) & $55(41.7)$ & $22(16.6)$ & & 13 (19.7) & $26(39.4)$ & $3(4.5)$ & $9(13.6)$ & 11 (16.7) & $4(6.1)$ & \\
\hline
\end{tabular}

PT, phototherapy; NS, not significant by $\chi^{2}$ analysis.

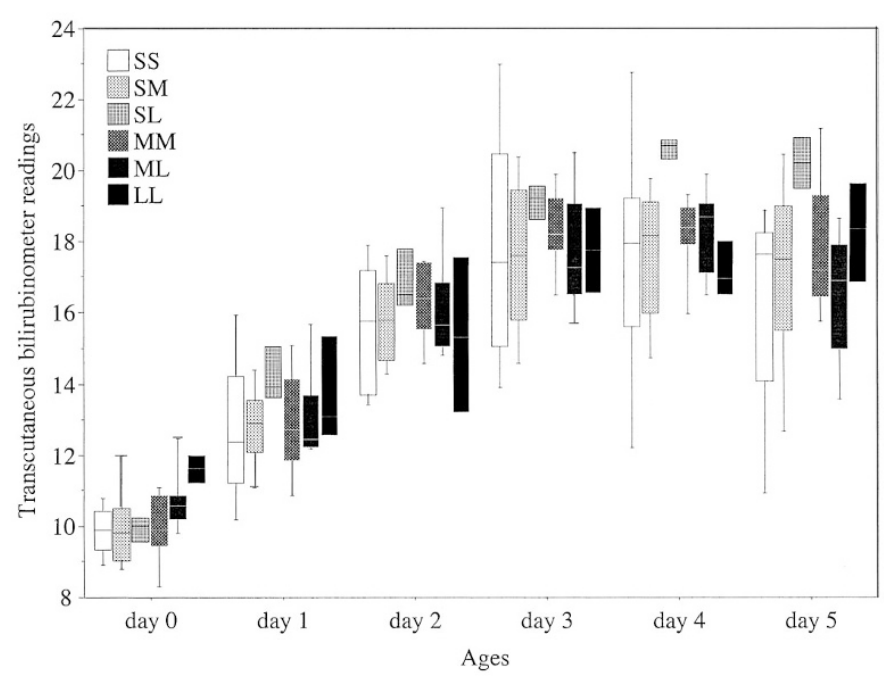

Figure 2. TCBR on $\mathrm{d} 0-5$ in the six genotypes of numbers of $(\mathrm{GT})_{\mathrm{n}}$ dinucleotide repeats according to the three allele classes. Boxes show median, $25 \%$, and $75 \%$, and bars are $10 \%$ and $90 \%$ for each group. No significant difference was seen with the Kruskal-Wallis test on each day.

group and the low $\mathrm{HbF} \%$ group on $\mathrm{d} 4$ and between the high $\mathrm{HbF} \%$ group and middle $\mathrm{HbF} \%$ group on $\mathrm{d} 5$. However, there was no significant difference among the three groups. As for characteristics, there were significant differences in gestational age and birth weight among those three groups (Table 3). Significant inverse correlations were observed between $\mathrm{HbF} \%$ and gestational age $(r=-0.45, p=0.001)$, and between $\mathrm{HbF} \%$ and birth weight $(r=-0.30, p=0.01)$. To decrease the effect of gestational age and birth weight, we analyzed the subjects within the range of mean $\pm 1.0 \mathrm{SD}$ of gestational age $(277.7 \pm 9.1 \mathrm{~d})$ and birth weight $(3159.5 \pm 317.1 \mathrm{~g})$. As shown in Figure 4, there was no significant difference in TCBR among the three groups.

We studied the relation between the types of ${ }^{\mathrm{A}} \gamma$-globin chain composition and TCBR. As shown in Figure 5, there were no

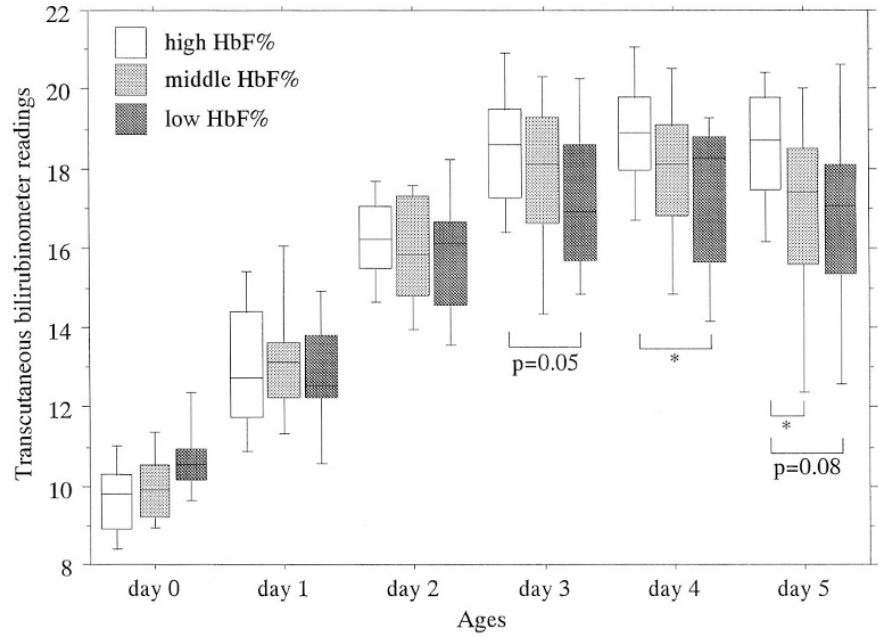

Figure 3. TCBR on $\mathrm{d} 0-5$ in the three groups of $\mathrm{HbF} \%$. Boxes show median, $25 \%$, and $75 \%$, and bars are $10 \%$ and $90 \%$ for each group. No significant difference was seen with the Kruskal-Wallis test among the three subgroups on each day. *Significant differences $(p<0.05)$ between two subgroups with Mann-Whitney $U$ test. $p=0.05, p=0.08 ; p$ value in Mann-Whitney $U$ test.

significant differences among the three types of ${ }^{\mathrm{A}} \gamma$-globin chain composition on $\mathrm{d} 0-5$. We also checked the TCBR of the six subjects with $\geq 80 \%$ of ${ }^{\mathrm{G}} \gamma \%$ and two subjects with $<50 \%$ of ${ }^{\mathrm{G}} \gamma \%$ compared with all other subjects and found no significant difference in the TCBR.

\section{DISCUSSION}

Neonatal hyperbilirubinemia is a physiologic phenomenon, but a significant difference is well known in its incidence and intensity among different races. Theoretically, indirect hyperbilirubinemia may be caused by either overproduction or impaired metabolism of bilirubin, or both. In 1998, we elucidated that the G71R mutation of the B-UGT gene is very common 
Table 3. Characteristics of the subjects in high, middle, and low $\mathrm{HbF} \%$ groups

\begin{tabular}{|c|c|c|}
\hline $\mathrm{HbF} \%$ & Gestational age $(\mathrm{d})^{* *}$ & Birth weight $(\mathrm{g})^{*}$ \\
\hline $\operatorname{High}(n=13)$ & $274.3 \pm 10.6$ & $2931.8 \pm 266.3$ \\
\hline Middle $(n=39)$ & $276.1 \pm 8.9$ & $3201.3 \pm 313.7]^{\dagger}$ \\
\hline Low $(n=17)$ & $283.9 \pm 4.8 \neg$. & $3237.6 \pm 296.2$ \\
\hline Total $(n=69)$ & لـ $277.7 \pm 9.1$ & $3159.5 \pm 317.1$ \\
\hline
\end{tabular}

High, $\mathrm{HbF} \%>90 \%$; middle, $\mathrm{HbF} \%$ ranged from 80 to 90\%; Low, $\mathrm{HbF} \%$ $<80 \%$.

$* p<0.05$; ** $p<0.01$ by one-way ANOVA; $\dagger p<0.01$ by one-way ANOVA with Fisher's protected least significant difference.

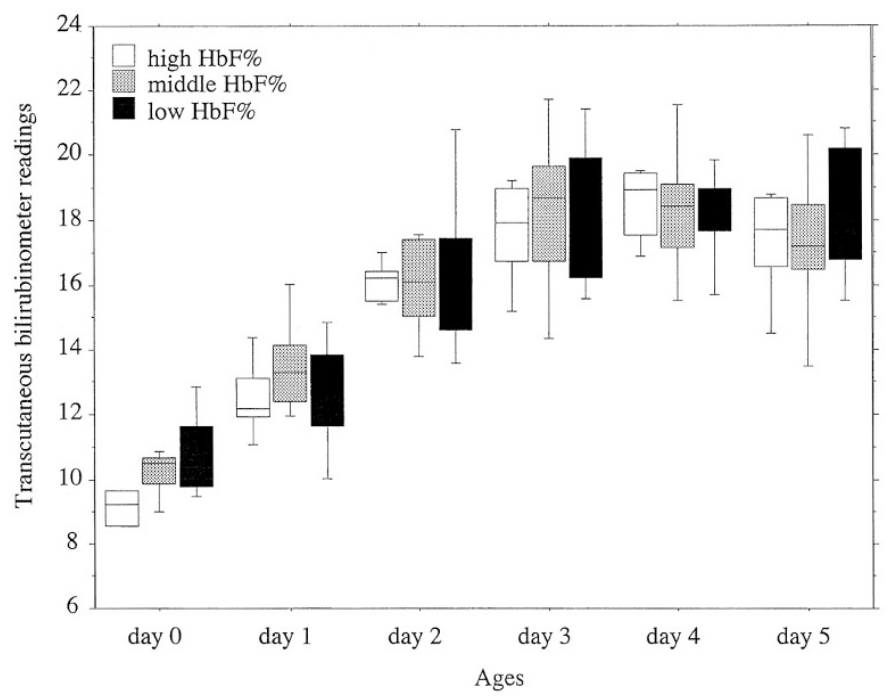

Figure 4. TCBR on $\mathrm{d} 0-5$ in the three groups of $\mathrm{HbF} \%$, excluding the subjects outside the range of mean $\pm 1.0 \mathrm{SD}$ of gestational age and birth weight. Boxes show median, 25\%, and $75 \%$, and bars are $10 \%$ and $90 \%$ for each group. No significant difference was seen with the Kruskal-Wallis test on each day.

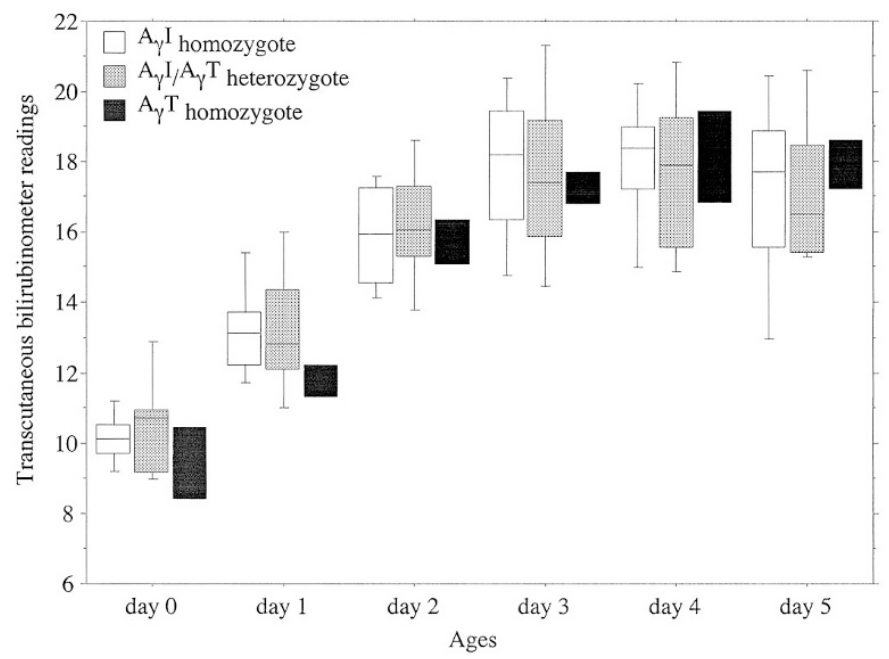

Figure 5. TCBR on d $0-5$ in the three compositions of the $\gamma$-globin chain. Boxes show median, $25 \%$, and $75 \%$, and bars are $10 \%$ and $90 \%$ for each group. No significant difference was seen with the Kruskal-Wallis test on each day.

among Japanese, Koreans, and Chinese and is associated with the high incidence and severity of neonatal hyperbilirubinemia in Japanese infants $(4,5)$. However, we noticed that half of the neonates with severe neonatal hyperbilirubinemia did not carry the G71R mutation. In addition, there are several studies that reported that an increase in bilirubin production is possibly associated with the neonatal hyperbilirubinemia in Asians including Japanese (6-9). In the present study, we tried to identify the genetic factors that may cause the overproduction of bilirubin leading to neonatal hyperbilirubinemia, and investigated the HO-1 gene, a gene encoding a key enzyme of heme metabolism, and $\gamma$-globin chain composition as factors possibly associated with heme load in neonates.

$\mathrm{HO}$ is a rate-limiting enzyme in the metabolic pathway of heme degradation and has three isoforms-HO-1, HO-2, and HO-3. HO-1 is widely distributed in tissues, predominantly in the spleen $(18,19)$, and is inducible with various stimuli such as hemin, heat shock, ischemia, and so on. HO-1 has approximately 10-fold higher $V_{\max }$ and one half of $K_{\mathrm{m}}$ compared with HO-2 $(19,20)$. HO-2 locates mainly in the brain and testis, and is constitutively active and unresponsive to any inducers of HO-1 (19, 20). HO-3 is ubiquitously expressed, but has an extremely low catalytic activity (19). In addition, a patient with HO-1 deficiency showed a symptom of impaired $\mathrm{Hb}$ heme degradation (21). On the basis of those biochemical findings, it is suggested that HO- 1 plays a predominant role in the degradation of $\mathrm{Hb}$ heme, a major source of bilirubin.

We first determined the sequences of the HO- 1 gene of the subjects with neonatal hyperbilirubinemia and could not find any mutations in the promoter and coding regions of the HO- 1 gene that would cause a change in the transcription or the kinetics leading to more enzyme activity. We only detected a polymorphic $(\mathrm{GT})_{\mathrm{n}}$ dinucleotide repeat sequence in the promoter region, which modulates the gene transcription. Longer $(\mathrm{GT})_{\mathrm{n}}$ repeat sequences are known to reduce the transcription of the HO-1 gene. It was probable that most Japanese neonates and the subjects who had undergone phototherapy due to severe neonatal hyperbilirubinemia (PT group) would have shorter $(\mathrm{GT})_{\mathrm{n}}$ repeats compared with most Caucasians and the subjects who had not undergone phototherapy (non-PT group), respectively. There was a significant difference in the distribution of the numbers of $(\mathrm{GT})_{\mathrm{n}}$ repeats of the HO-1 gene between Japanese and German subjects. Japanese subjects had significantly shorter $(\mathrm{GT})_{\mathrm{n}}$ repeat alleles than German subjects, however, the Japanese also showed an increase in the allele frequency or the genotypes of longer $(\mathrm{GT})_{\mathrm{n}}$ repeats compared with the Germans. In addition, we did not find an increase in the allele frequency or the genotypes of shorter $(\mathrm{GT})_{\mathrm{n}}$ repeats in the PT group compared with the non-PT group, and a correlation between the genotypes of $(\mathrm{GT})_{\mathrm{n}}$ repeats and TCBR. We could not deny the possibility that the unique distribution of genotype of $(\mathrm{GT})_{\mathrm{n}}$ repeats in Japanese may be associated with severe neonatal hyperbilirubinemia, however, it is not probable that a genotype of $(\mathrm{GT})_{\mathrm{n}}$ repeats of the HO- 1 gene is a factor that directly causes severe neonatal hyperbilirubinemia in Japanese infants.

We then studied the relation between neonatal hyperbilirubinemia and the state of $\mathrm{Hb}$ switching or the phenotype of $\gamma$-globin chain isoforms. Analysis of the neonates of $\geq 36 \mathrm{wk}$ of gestational age showed that $\mathrm{HbF} \%$ was apparently correlated with TCBR on d 3-5. However, the group with higher $\mathrm{HbF} \%$ consisted of the neonates of younger gestational ages and lower birth weights. A significant correlation between 
$\mathrm{HbF} \%$ and TCBR was probably caused by the heterogeneity of each group in gestational age and birth weight. A correlation between $\mathrm{HbF} \%$ and TCBR reflected a correlation between immaturity of the neonates and neonatal hyperbilirubinemia. The present study also showed that there was no correlation between the phenotype of $\gamma$-globin chain isoforms and TCBR. We could not find a significant relation between the genetic factors associated with a $\mathrm{Hb}$ switching of the $\gamma$ - to $\beta$-globin chain or a specific phenotype of $\gamma$-globin chain isoforms and neonatal hyperbilirubinemia in Japanese.

As for the bilirubin production, some studies reported that the bilirubin production estimated by $\mathrm{CO}$ production was increased in Japanese or Asian neonates compared with that in other races (6-9), but other studies did not (9, 22-24). One study of Japanese neonates collected specimens from those who lived in Japan (6), and other studies of Japanese used specimens from those who lived in other countries $(22,24)$. These data may suggest that some environmental factors are associated with severe neonatal hyperbilirubinemia in Japanese.

Uetani et al. (25) reported that blood carboxyhemoglobin $(\mathrm{HbCO})$ corrected for ambient $\mathrm{CO}(\mathrm{HbCOc})$ level in $\mathrm{ABO}-$ compatible Japanese neonates with hyperbilirubinemia was higher compared with that in ABO-compatible Japanese neonates without hyperbilirubinemia at $72 \mathrm{~h}$ of age. Okumura et al. (26) found that end-tidal CO (ETCO) corrected for ambient CO (ETCOc) levels in hyperbilirubinemic neonates was significantly higher than that in nonhyperbilirubinemic neonates at $42,48,54$, and $66 \mathrm{~h}$ of age. CO production can serve as an index of heme degradation and bilirubin formation because of the equimolar production with bilirubin by the reaction of $\mathrm{HO}$. The generated $\mathrm{CO}$ binds to the $\mathrm{Hb}$ in the red cells to form $\mathrm{HbCO}$, and the $\mathrm{HbCO}$ levels are in equilibrium with $\mathrm{CO}$ excretion via the lungs under steady-state conditions. Therefore, measurements of pulmonary excretion rate of $\mathrm{CO}$ or ETCOc as well as $\mathrm{HbCOc}$ are also good indices of heme degradation and bilirubin production. Measurements of $\mathrm{HbCO}$, however, are disturbed by $\mathrm{HbF}$ or the blood oxygen saturation in some methods (9). ETCOc is probably influenced by neonatal pulmonary function. In addition, $\geq 10 \% \mathrm{CO}$ may be nonenzymatically produced from nonheme resources such as photooxidation of organic compounds and lipid peroxidation (8). It is unclear whether an increase in $\mathrm{CO}$ production in neonatal hyperbilirubinemia exactly reflects an increase in $\mathrm{HO}$ reaction, and whether an increased $\mathrm{HO}$ reaction contributes to neonatal hyperbilirubinemia. However, the HO reaction is probably increased in Japanese and other Asian neonates with hyperbilirubinemia as a result of genetic and/or environmental factors. HO-1 is induced by various stresses. It is possible that a stress-inducing HO-1 may also disturb the bilirubin metabolism coincidentally.

In conclusion, we analyzed the HO-1 gene in Japanese neonates with severe hyperbilirubinemia and found no mutation except for the polymorphic $(\mathrm{GT})_{\mathrm{n}}$ repeats in the promoter region. We detected a significant difference in the allele frequencies of each number of $(\mathrm{GT})_{\mathrm{n}}$ repeats between Japanese and German subjects. However, we could not find a relation between those polymorphisms and neonatal hyperbilirubinemia. We also analyzed the state of $\mathrm{Hb}$ switching of the $\gamma$ to $\beta$-globin chain and the phenotype of $\gamma$-globin chain isoforms in cord blood, and found no relation between the HbF composition and neonatal hyperbilirubinemia. Further studies are required to elucidate the genetic or environmental factors in neonatal hyperbilirubinemia in Japanese infants.

\section{REFERENCES}

1. Maisels MJ 2000 Epidemiology and causes of indirect hyperbilirubinemia. In: Maisels MJ, Watchko JF (eds) Neonatal Jaundice. Harwood Academic Publishers, Amsterdam, pp 37-49

2. Halamek LP, Stevenson DK 1997 Neonatal jaundice and liver disease. In: Fanaroff AA, Martin, RJ (eds) Neonatal-Perinatal Medicine. Mosby-Year Book, St. Louis, pp 1345-1389

3. Kawade N, Onishi S 1981 The prenatal and postnatal development of UDPglucuronyltransferase activity towards bilirubin and the effect of premature birth on this activity in the human liver. Biochem J 196:257-260

4. Akaba K, Kimura T, Sasaki A, Tanabe S, Ikegami T, Hashimoto M, Umeda H, Yoshida H, Umetsu K, Chiba H, Yuasa I, Hayasaka K 1998 Neonatal hyperbilirubinemia and mutation of the bilirubin uridine diphosphate-glucuronosyltransferase gene: a common missense mutation among Japanese, Koreans and Chinese. Biochem Mol Biol Int 46:21-26

5. Akaba K, Kimura T, Sasaki A, Tanabe S, Wakabayashi T, Hiroi M, Yasumura S, Maki K, Aikawa S, Hayasaka K 1999 Neonatal hyperbilirubinemia and a common mutation of the bilirubin uridine diphosphate-glucuronosyltransferase gene in Japanese. J Hum Genet 44:22-25

6. Fischer AF, Nakamura H, Uetani Y, Vreman HJ, Stevenson DK 1988 Comparison of bilirubin production in Japanese and Caucasian infants. J Pediatr Gastroenterol Nutr 7:27-29

7. Bartoletti AL, Stevenson DK, Ostrander CR, Johnson JD 1979 Pulmonary excretion of carbon monoxide in the human infant as an index of bilirubin production. I. Effects of gestational and postnatal age and some common neonatal abnormalities. J Pediatr 94:952-955

8. Stevenson DK, Vreman HJ, Wong RJ, Contag CH 2001 Carbon monoxide and bilirubin production in neonates. Semin Perinatol 25:85-93

9. Stevenson DK 1992 The carboxyhemoglobin method for estimating bilirubin production in neonates. Japanese studies. Clin Pediatr (Phila) 31:708-711

10. Okinaga S, Takahashi K, Takeda K, Yoshizawa M, Fujita H, Sasaki H, Shibahara S 1996 Regulation of human heme oxygenase-1 gene expression under thermal stress. Blood 87:5074-5084

11. Yamada N, Yamaya M, Okinaga S, Nakayama K, Sekizawa K, Shibahara S, Sasaki H 2000 Microsatellite polymorphism in the heme oxygenase-1 gene promoter is associated with susceptibility to emphysema. Am J Hum Genet 66:187-195 (erratum in 2001;68:1542)

12. Huisman TH, Reese AL, Gardiner MB, Wilson JB, Lam H, Reynolds A, Nagle S, Trowell P, Zeng YT, Huang SZ, Sukumaran PK, Miwa S, Efremov GD, Petkov G, Sciarratta GV, Sansone G 1983 The occurrence of different levels of G gamma chain and of the A gamma $\mathrm{T}$ variant of fetal hemoglobin in newborn babies from several countries. Am J Hematol 14:133-148

13. Harano T, Harano K, Ukita M, Wada Y, Hayashi A, Ohba Y, Miyaji T, Kutlar F, Huisman TH 1988 Characterization of abnormalities in the $\gamma$-globin gene arrangements of Japanese newborns. Hemoglobin 12:723-739

14. White JM, Frost BA 1984 Investigation of the haemoglobinopathies. In: Dacie JV, Lewis SM (eds) Practical Haematology. Churchill Livingstone, Edinburgh, pp 179-199

15. Tsuchiya T, Nozawa Y, Igarashi Y, Kajita A 1983 Gamma chain heterogeneity of fetal hemoglobin in Japanese newborn and adult. Dokkyo J Med Sci 10:13-27

16. Enoki Y, Ohga Y, Sakata S, Kohzuki H 1991 Postnatal transition of gamma-globin gene expression in normal Japanese population. Br J Haematol 79:628-633

17. Shimizu K, Harano T, Harano K, Miwa S, Amenomori Y, Ohba Y, Kutlar F, Huisman TH 1986 Abnormal arrangements in the alpha- and gamma-globin gene clusters in a relatively large group of Japanese newborns. Am J Hum Genet 38:45-58

18. Rodgers PA, Stevenson DK 1990 Developmental biology of heme oxygenase. Clin Perinatol 17:275-291

19. Elbirt KK, Bonkovsky HL 1999 Heme oxygenase: recent advances in understanding its regulation and role. Proc Assoc Am Physicians 111:438-447

20. Maines MD 1988 Heme oxygenase: function, multiplicity, regulatory mechanisms, and clinical applications. FASEB J 2:2557-2568

21. Yachie A, Niida Y, Wada T, Igarashi N, Kaneda H, Toma T, Ohta K, Kasahara Y, Koizumi S 1999 Oxidative stress causes enhanced endothelial cell injury in human heme oxygenase-1 deficiency. J Clin Invest 103:129-135

22. Cohen RS, Hopper AO, Ostrander CR, Stevenson DK 1982 Total bilirubin production in infants of Chinese, Japanese, and Korean ancestry. J Formos Med Assoc 81:1524-1529

23. Stevenson DK, Vreman HJ, Oh W, Fanaroff AA, Wright LL, Lemons JA, Verter J, Shankaran S, Tyson JE, Korones SB, Bauer CR, Stoll BJ, Papile LA, Okah F, Ehrenkranz RA 1994 Bilirubin production in healthy term infants as measured by carbon monoxide in breath. Clin Chem 40:1934-1939

24. Balaraman V, Pelke S, DiMauro S, Cheung S, Stevenson DK, Easa D 1995 End-tidal carbon monoxide in newborn infants: observations during the 1st week of life. Biol Neonate 67:182-185

25. Uetani Y, Nakamura H, Okamoto O, Yamazaki T, Vreman HJ, Stevenson DK 1989 Carboxyhemoglobin measurements in the diagnosis of ABO hemolytic disease. Acta Paediatr Jpn 31:171-176

26. Okuyama H, Yonetani M, Uetani Y, Nakamura H 2001 End-tidal carbon monoxide is predictive for neonatal non-hemolytic hyperbilirubinemia. Pediatr Int 43:329-333 